\title{
Stress intensity factors for mixed-mode crack growth in imitation models under biaxial loading
}

\author{
R.R. Yarullin, V.N. Shlyannikov, I.S. Ishtyriakov, M.M. Yakovlev \\ Institute of Power Engineering and Advanced Technologies FRC Kazan Scientific Center of RAS, Russia \\ yarullin_r@mail.ru,shlyannikov@mail.ru,ivan_200999@mail.ru,yakovlev.mikhail.m@yandex.ru
}

\begin{abstract}
In this paper, a procedure to calculate stress intensity factors for imitation models of titanium alloys is proposed. Fatigue cracks are detected in a disk and blade "dovetail type" attachment in service. Based on the attachment dimensions and taking into account the biaxial loading conditions of the rotating compressor disk, two imitation model geometries of gas turbine engine compressor disks are developed. To accurately verify the biaxial loading conditions, the first imitation model of constant thickness is used. In order to completely reproduce the geometry of the compressor disk and the conditions of mixed mode crack growth, the second imitation model with a reduced cross section is proposed. Fatigue crack growth experiments of the imitation models are carried out at room temperature on a biaxial testing machine. Two different stress ratio values are applied several times to each imitation model in order to establish the experimental positions of the crack fronts. The elastic and plastic stress intensity factors used to represent the experimental results are computed using full-size 3D finite element analyses of the imitation models with surface quarter elliptical and throughthickness cracks. The use of the plastic stress intensity factor as a unified parameter for assessing the fracture resistance of materials and structures is supported. The advantages of using the computational and experimental results of imitation model II for verification and development of modern crack growth rates and lifetime prediction models are stated.
\end{abstract}

KeYwords. Titanium alloy; Mixed-mode; Crack growth; Stress intensity factors; Biaxial loading; Imitation modelling.

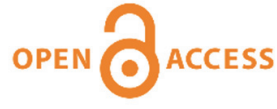

Citation: Yarullin, R.R., Shlyannikov, V.N. Ishtyriakov, I.S., Yakovlev, M.M, Stress intensity factors for mixed-mode crack growth in imitation models under biaxial loading, Frattura ed Integrità Strutturale, 53 (2020) 210-222.

Received: 12.04 .2020

Accepted: 06.05.2020

Published: 01.07.2020

Copyright: (C) 2020 This is an open access article under the terms of the CC-BY 4.0, which permits unrestricted use, distribution, and reproduction in any medium, provided the original author and source are credited.

\section{INTRODUCTION}

$\mathrm{M}$ anufacturing flaws, mechanical damages, pre-cracks and crack initiations due to cyclic loading often lead to undetected crack propagation in commercial structures, e.g. in aircraft components. After a crack develops, cyclic loading can cause the crack to grow into any shape with arbitrary orientations, depending on the geometry of the structure and the boundary and loading conditions. The failure of gas turbine engine (GTE) compressor 
disks, which are an integral component in gas turbine assemblies, can lead to catastrophic aircraft damage. Therefore, it is crucial to predict the crack growth in all stages of development and maintenance in order to prevent such scenarios.

In most cases, fatigue life prediction for rotating disks can be divided into two parts: the first part is related to a numerical 3D full-size stress-strain state analysis and numerical simulations of fatigue crack growth processes in real structures, and the second part is the lifetime assessment on the basis of full-scale fatigue experiments or imitation model tests.

In the last 30 years, numerous fatigue crack growth concepts based on numerical simulations have been established to predict lifetimes of real structures and components under service loading conditions. These approaches are also implemented in many three-dimensional software tools, such as FRANC3D [1], ZENCRACK [2], ABAQUS [3], ADAPCRACK3D [4], and BEASY [5]. Crack growth is generally simulated in a stepwise manner, and the stress intensity factors (SIFs) are calculated by means of the J-integral technique for each new crack front. The crack path is assessed via the maximum tangential stress (MTS) criterion. The finite element method (FEM), boundary element method (BEM), and dual boundary element method (DBEM) have been established to calculate SIFs.

Simulation of fatigue crack growth and fracture in components and structures such as components of hydraulic presses, truck pistons, hammer mill shafts, and railway wheels was carried out using a commercial finite element (FE)-solving program [6]. The energy release rate of crack propagation, and thus the SIFs $K_{I}, K_{I I}$, and $K_{I I I}$ were calculated along the 3D-crack front from the nodal forces and displacements. After checking if the crack propagation criterion was fulfilled, the crack growth direction (in case of a growing crack) was determined for every node of the crack front, and the simulation continued until $\Delta \mathrm{K}_{\mathrm{eq}}=\Delta \mathrm{K}_{\mathrm{Ic}}$.

A coupled FEM-DBEM procedure based on the superposition principle applied to fracture mechanics was adopted to simulate a fracture process on a real aircraft gas turbine engine [7]. The approach was fully automated and allowed predicting SIFs, crack-growths, and paths with high accuracy. The initial crack was inserted in the most critical point of the compressor stage of interest, as acquired from the experimental results. A good agreement between the numerical crack paths calculated with FEM-DBEM and FEM-FEM approaches was shown, but the numerical path did not match the experimental path, probably because of the lack of relevant loading conditions coming from the pressure on the blades, the residual stresses, transients, and blade vibrations, etc.

The aim of the study in [8] was to present two distinct approaches to perform fatigue crack-growth simulations in a highpressure compressor disc of the D-36 gas turbine engine. The adopted approaches were based on a full FEM modelling and on a particular variant of the FEM-DBEM sub modeling technique, in which only the crack faces were loaded. Although the fracture approaches adopted different modelling strategies and different criteria for calculating the fracture parameters, they proved to be very accurate in calculating SIFs, kink angles, and eventually the crack-growth rates. Moreover, a numerical-experimental comparison was also provided, and satisfactory agreement was observed.

Lifetime assessment of rotating disks based on full-scale fatigue experiments on electrohydraulic stands was very popular in the 1980s. In these tests, the disc remains stationary and the loads are transmitted from hydraulic power cylinders through the blade attachment slots. Combining the advantages of the electrohydraulic load control techniques with the advantages of full-scale disc tests, the stand was a powerful tool for studying disc service life [9].

However, high cost and long durations of full-scale tests and low statistical reliabilities of test results led to the subsequent development and realization of imitation modeling principles. Imitation modeling is used for analysis and prevention of operation failures of GTE turbine discs [10]. The critical fracture location in selected turbine discs was the bolthole, which was modeled by a bolthole specimen (BHS) cut out from the turbine disc. The geometric parameters of the BHS and its loading type were selected so to achieve an acceptable stress distribution in a critical region both for the turbine disc and the BHS. Imitation modeling has shown significant advantages during the design, operation, and repair processes of aircraft engine components.

Shlyannikov et al. [11] proposed two geometries of the imitation models of GTE compressor disks. The loading conditions of the imitation models were found, and numerically verified to reproduce the loading conditions in the compressor disk during operation. It was demonstrated that the biaxially loaded imitation model II reproduced the state of the critical zone of the compressor disk at operation most accurately. It was also demonstrated that the proposed imitation modelling principles allow the estimating residual life of the compressor disk, taking into account crack initiation and growth at critical zones.

Shanyavskiy [12] shows that the predominant failure mechanism for gas turbine disks is the low cycle fatigue (LCF) resulting in the formation of a fracture relief that reflects the two-phase $(\alpha+\beta)$ lamellar structure of the titanium alloy, and a fragmentary fatigue striation formation. Such loading conditions lead to fatigue crack initiations and their propagation up to a critical zone in rotating disks. Most of the critical zones are characterized by the presence of plastic deformations, in which the effective stresses exceed the yield strengths of the materials even at room temperature. These circumstances 
assume the application of nonlinear fracture and continuum damage mechanics approaches to power equipment, and for lifetime prediction of aviation GTE components [13-15].

Experience shows that the results obtained by the considered procedure of numerical simulation are in good agreement with the experimental results concerning fatigue crack growth tests and fatigue life determination [16]. However, in the case of nonlinear cyclic deformation, damage accumulation, growth, and the fatigue life of structural components are underestimated by the numerical procedure. This is not only due to the simplified axis symmetric modeling and the choice of the elastic crack growth constants, but also due to the change in mixed-mode loading conditions along crack fronts at operation. Under these conditions, a key point of aircraft GTE component life analysis is knowledge of the elastic-plastic fracture mechanical parameters for the surface and through-thickness cracks, with regard to the three-dimensional geometry under complex stress loadings.

This paper provides the determination of elastic and plastic SIFs for various crack sizes obtained by experiments on biaxially loaded imitation models and establish the advantages of integrating numerical analyses and experimental research for verification and development of modern crack growth rates and lifetime prediction models.

\section{MIXED MODE CRACK GROWTH PARAMETERS}

\section{Biaxial loading conditions}

$\mathrm{M}$ any engineering components that undergo fatigue loading experience biaxial or multiaxial stress states. Rotating GTE elements like turbine or compressor discs are typical examples [17]. There is sound experimental evidence that the fatigue crack growth rate is strongly influenced by the biaxial loading conditions [14].

Yarullin et al. [18] performed a detailed numerical analysis of the stress-strain state (SSS) a of full-size 3D FE model of a compressor disk with blades under operation loading conditions. Their results show that the equivalent stress peak mainly occurred close to the outer free surface of the slot key, where a corner crack was likely to nucleate and grow due to the cyclic loading.

The distribution of the nominal stress biaxiality and triaxiality parameters along the radius of the compressor disk from the inner to the outer diameters are determined by the following equation [19]:

$$
\eta=\sigma_{r r} / \sigma_{\theta \theta}, h=\sigma_{k k} /\left(3 \sqrt{3 / 2 \cdot S_{i j} S_{i j}}\right)
$$

where $\sigma_{\mathrm{rr}}$ and $\sigma_{\theta \theta}$ are the radial and tangential (or hoop) elastic-plastic stresses, respectively. $\sigma_{\mathrm{kk}}$ and $\mathrm{S}_{\mathrm{ij}}$ are the hydrostatic and deviatoric stresses, respectively.

Fig. 1 shows the distributions of the nominal stress biaxiality and triaxiality parameters related to the cross section of the compressor disk, which is located between the two disk and blades «dovetail type» attachments. In Fig. 1, the solid line indicates the middle plane of the disk, and the dashed line depicts the outer free surface of the compressor disk. As it follows from these results, the state of the stresses in the 3D full-size compressor disc obtained from the FE calculation was found to be biaxial, and the biaxiality and triaxiality stress ratios near the key slot reach up to $\eta=0.50$ and $h=0.60$, respectively. Therefore, taking into account the biaxial loading conditions, mixed-mode crack growth behavior in critical zones of compressor disks can be evaluated.

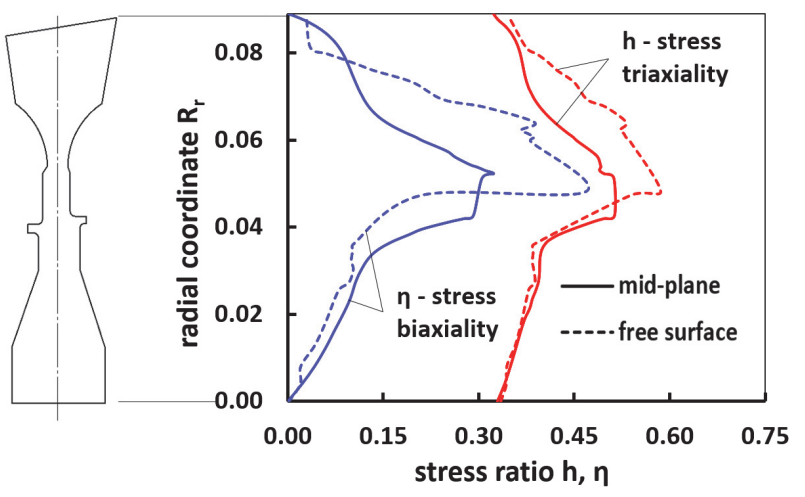

Figure 1: Distribution of stress ratios along the disk cross section. 


\section{Equivalent stress intensity factor}

Mixed-mode crack growth behaviors often occur in real structures with complex geometry and loading conditions that might additionally change during crack growth. An existing crack under Mode I-loading conditions will propagate within the original crack plane. Mode II-loading generally leads to a kinking of the crack, while Mode III causes a twisting of the crack front. To study the influence of the mixed-mode loading conditions on material fracture resistance parameters, it is necessary to calculate three fracture parameters characterized by the SIFs $K_{I}, K_{\text {II }}$, and $K_{\text {III }}$.

They are assigned to the basic fracture modes of a crack and defined by Eqn. (2). The SIF depends on the stress $\left(\sigma_{\mathrm{y}}, \tau_{\mathrm{xy}}\right.$ or $\left.\tau_{\mathrm{yz}}\right)$, the crack length $a$, and on the boundary correction factors ( $\mathrm{Y}_{\mathrm{I}}, \mathrm{Y}_{\mathrm{II}}$ or $\left.\mathrm{Y}_{\mathrm{III}}\right)$. If the loading of a structure creates a nonsymmetrical and singular stress field near the crack front, then the crack front deforms in a way that not only an opening, but also a planar and non-planar displacement of both crack flanks can be found [20]:

$$
K_{I}=\sigma_{y} \sqrt{\pi a} \cdot Y_{I}, K_{I I}=\tau_{x y} \sqrt{\pi a} \cdot Y_{I I}, K_{I I I}=\tau_{y z} \sqrt{\pi a} \cdot Y_{I I I}
$$

Shlyannikov [21] generalized the numerical method to calculate the geometry dependent correction factors $\mathrm{Y}_{\mathrm{I}}, \mathrm{Y}_{\mathrm{II}}$, and $\mathrm{Y}_{\mathrm{III}}$ for the SIFs $\mathrm{K}_{\mathrm{I}}, \mathrm{K}_{\mathrm{II}}$, and $\mathrm{K}_{\mathrm{III}}$ under mixed mode fracture. The present study explores the direct use of FE solution results for calculating the SIFs $\mathrm{K}_{\mathrm{I}}, \mathrm{K}_{\mathrm{II}}, \mathrm{K}_{\mathrm{III}}$, ahead of the crack tip $\left(\theta=0^{\circ}\right)$ :

$$
K_{I}=\sigma_{\theta \theta}^{F E M} \sqrt{2 \pi r}, K_{I I}=\sigma_{r \theta}^{F E M} \sqrt{2 \pi r}, K_{I I I}=\sigma_{\theta \omega}^{F E M} \sqrt{2 \pi r}
$$

where $r, \theta$, and $\omega$ are polar coordinates centered at the crack tip, and $\sigma_{i}^{F E M}$ are the stresses obtained from the FE solution. Chang et al. [22] proposed a concept of effective SIF for three mixed modes. One can simply calculate the effective SIF and evaluate the fracture just by comparing it with the toughness. A new expression for the elastic equivalent SIF in which the in-plane angle of crack deviation $\theta^{*}$ is included in an explicit form has been proposed in [22]:

$$
K_{\text {eqv }}\left(\theta^{*}\right)=(1+v) \cos ^{2}\left(\frac{\theta^{*}}{2}\right)\left\{\frac{(1-v)}{2}\left[K_{1}^{2}\left(1+\cos \theta^{*}\right)-4 K_{I} K_{I I} \sin \theta^{*}+K_{I I}^{2}\left(5-3 \cos \theta^{*}\right)\right]+K_{I I I}^{2}\right\}
$$

In turn, the branching fracture angle is determined from the equation:

$$
\Theta=\left\{\frac{(1-v)}{2}\left[K_{I}^{2}\left(\sin \frac{\theta^{*}}{2}+\sin \frac{3}{2} \theta^{*}\right)+4 K_{I} K_{I I} \cos \frac{3}{2} \theta^{*}-K_{I I}^{2}\left(3 \sin \frac{3}{2} \theta^{*}-5 \sin \frac{\theta^{*}}{2}\right)\right]+K_{I I I}^{2} \sin \frac{\theta^{*}}{2}\right\}=0
$$

\section{Plastic stress intensity factor}

The expediency of using the plastic SIF to characterize the fracture resistance as the self-dependent unified parameter through examples of using a cruciform specimens, compact tension-shear specimens, real components, a wide range of steels, and titanium and aluminum alloys at different temperatures is discussed in [13-15, 18, 23].

The plastic SIF $K_{M}^{P}$ in mixed-mode small-scale yielding can be expressed directly in terms of the corresponding elastic SIFs using Rice's J-integral. The J-integral formulation for general mixed mode conditions I, II and III leads to the following expression given by Rigby and Aliabadi [24]:

$$
J_{1}=J^{I}+J^{I I}+J^{I I}=\frac{1}{E^{*}}\left(K_{I}^{2}+K_{I I}^{2}\right)+\frac{1}{2 G} K_{I I I}^{2}
$$

where $E$ is the Young's modulus for plane stress, $E^{*}=E /\left(1-v^{2}\right)$ for plane strain, $G$ is the shear modulus and $v$ is the Poisson's ratio.

According to Hutchinson [25, 26] and Shih [27] for a crack subjected to mixed-mode loading in nonlinear strain hardening materials described by the Ramberg-Osgood constitutive equation, the Rice's J-integral can be expressed directly through the plastic $\operatorname{SIF} K_{M}^{P}$ by the following equation: 


$$
\frac{L \sigma_{0}^{2}}{E} \int_{\Gamma_{2}}\left(\bar{W} d y-\bar{\sigma}_{i j} n_{i} \bar{u}_{i, x} d s\right)=\frac{\bar{\alpha} \sigma_{0}^{2}}{E}\left(\bar{K}_{M}^{P}\right)^{n+1} \bar{r}^{(n+1)(\lambda-2)+1} \cdot I_{n}\left(\theta^{*}\right)
$$

where $\bar{\alpha}$ is the strain hardening coefficient and $n$ is the strain hardening exponent. In Eqn. (7) the stress tensor and displacements are both normalized by the yield stress $\sigma_{0}: \bar{\sigma}_{i j}=\sigma_{i j} / \sigma_{0}$ and $\bar{u}_{i}=u_{i} E / \sigma_{0} L . L$ is the cracked body characteristic size. Eqn. (7) contains the numerical governing parameter of the crack-tip elastic-plastic stress-strain field in the form of the $I_{n}\left(\theta^{*}\right)$-integral that depends on the in-plane mixed mode branching fracture angle $\theta^{*}$, and is a function of the material strain hardening exponent $n$, angular dimensionless stress $\tilde{\sigma}_{i j}(\theta)$, and displacement $\tilde{u}_{i}(\theta)$ distributions.

Shlyannikov and Tumanov [28, 29] have extended the Hutchinson [25, 26] and Shih [27] solutions, and introduced a new numerical method to obtain an accurate description for the distribution along the crack front of the $I_{n}\left(\theta^{*}\right)$-integral. This method combined the knowledge of the dominant singular solution with the FE technique:

$$
\begin{aligned}
& I_{n}^{F E M}\left(\theta, \theta^{*}, n,(a / L)\right)=\int_{-\pi}^{\pi} \Phi^{F E M}\left(\theta, \theta^{*}, n,(a / L)\right) d \theta \\
& \Phi^{F E M}\left(\theta, \theta^{*}, n,(a / L)\right)=\frac{n}{n+1}\left(\tilde{\sigma}_{e}^{n+1}\right)^{F E M} \cos \theta-\left[\tilde{\sigma}_{r r}^{F E M}\left(\tilde{u}_{\theta}^{F E M}-\frac{d \tilde{u}_{r}^{F E M}}{d \theta}\right)-\tilde{\sigma}_{r \theta}^{F E M}\left(\tilde{u}_{r}^{F E M}+\frac{d \tilde{u}_{\theta}^{F E M}}{d \theta}\right)\right] \sin \theta- \\
& -\frac{1}{n+1}\left(\tilde{\sigma}_{r r}^{F E M} \tilde{u}_{r}^{F E M}+\tilde{\sigma}_{r \theta}^{F E M} \tilde{u}_{\theta}^{F E M}\right) \cos \theta .
\end{aligned}
$$

The $J$-integral formulation for small-scale yielding conditions leads to the equality of Eqn. (6) and Eqn. (7), and the expression for the plastic SIF $K_{M}^{P}$ under mixed-mode fracture given by:

$$
\bar{K}_{M}^{P}=\left[\left(\frac{K_{e q \nu}}{\sigma_{0}^{2}}\right) \frac{1}{\bar{\alpha} I_{n}\left(\theta^{*}\right) L}\right]^{\frac{1}{n+1}}
$$

where $K_{\text {eqv }}$ is the equivalent elastic SIF as a function of the mode I, II and III fractures (Eqn. (4)).

\section{SUBJECT OF THE STUDY, MATERIAL PROPERTIES, AND EXPERIMENTAL CRACK PATHS}

7 he subject of this study is imitation models of high-pressure compressor disks of D-36 aircraft GTE. Fatigue cracks are detected in a disk and blade "dovetail type" attachment in service [18]. Based on the attachment dimensions and according to the basic principles of imitation modelling, taking into account the biaxial loading conditions of the rotating compressor disk, two geometries of imitation models of GTE compressor disks have been developed [11]. To accurately verify the biaxial loading conditions, the imitation model I of constant thickness is used (Fig. 2a). In order to fully reproduce the geometry of the compressor disk and the conditions of mixed mode crack growth, the imitation model II with reduced cross section is proposed (Fig. 2b). This imitation model fully reproduces the cross section of the real compressor disk in the range from the compensation holes to the disk and blade attachment area. The fatigue tests of the imitation models were carried out with a biaxial testing machine at a frequency of $5 \mathrm{~Hz}$ at room temperature, and with the stress ratio $R_{s}=0.1$, (Fig. 2c). The testing machine is equipped with four axial load cells of $50 \mathrm{kN}$ capacity. The tests of the imitation models were performed by applying in-phase forces along two axes $P_{x}=38 \mathrm{kN}$ and $P_{y}=19 \mathrm{kN}$, with stress biaxiality ratio $\eta=0.5$. The failure criterion is the condition when the growing crack reaches the area of the compensation hole. All tests were carried out with sinusoidal loading with load control. Load control was estimated to be better than $\pm 1 \%$. The crack growth was monitored using an optical microscope.

The material of the imitation models is two-phase titanium alloy VT3-1. The tensile properties of titanium alloy VT3-1 at room temperature were determined according to the ASTM standard E8 and are listed in Tab. 1. E is the Young's modulus, $\sigma_{\mathrm{s}}$ is the nominal ultimate tensile strength, $\sigma_{0}$ is the monotonic tensile yield strength, $\sigma_{\mathrm{u}}$ is the true ultimate 
tensile strength, $\delta$ is the elongation, $\psi$ is the reduction of area, $\mathrm{n}$ is the strain hardening exponent, and $\alpha$ is the strain hardening coefficient.

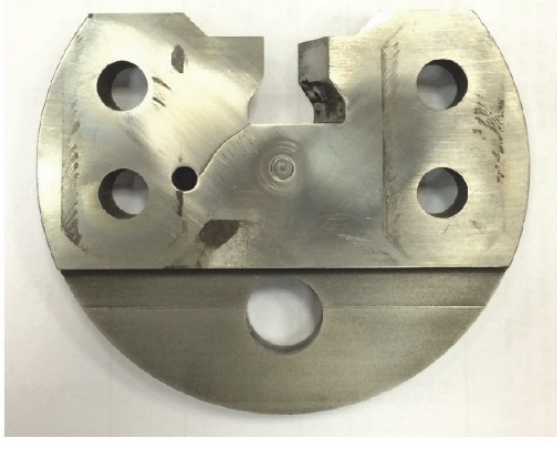

a)

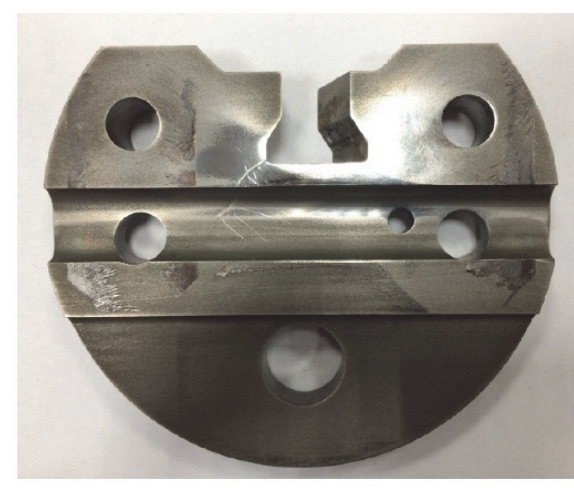

b)

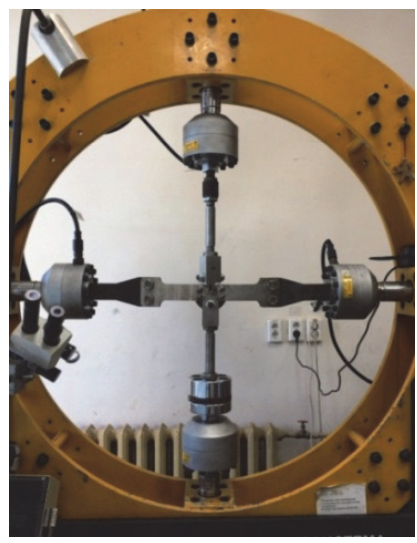

c)

Figure 2: Crack path for (a) imitation model I, (b) imitation model II, and (c) test equipment for biaxial loading.

\begin{tabular}{ccccccccccc}
\hline \multirow{2}{*}{ Material } & $\begin{array}{c}\text { Temperature, } \\
{ }^{\circ} \mathrm{C}\end{array}$ & $\begin{array}{c}\sigma_{0}, \\
\mathrm{MPa}\end{array}$ & $\begin{array}{c}\sigma_{\mathrm{S}}, \\
\mathrm{MPa}\end{array}$ & $\begin{array}{c}\sigma_{\mathrm{u}}, \\
\mathrm{MPa}\end{array}$ & $\alpha$ & $\mathrm{n}$ & $\mathrm{E}$, & $\delta$, & $\psi$, \\
$\%$ & \multirow{2}{*}{ VT3-1 } & & 1005 & 1073 & 1214 & 1.115 & 12.880 & 100.1 & 21 & 46 \\
\hline
\end{tabular}

Table 1: Main mechanical properties of two-phase titanium alloy at room temperature.

Two different stress ratio values (0.1 and 0.5) were applied several times to each model in order to fix the current crack front position. During each test, benchmarks were produced for each model by increasing the applied stress ratio from 0.1 to 0.5 at a constant value of the maximum cyclic nominal stress, while the surface crack length was increased by approximately $1 \mathrm{~mm}$. As shown in [23, 30, 31], the benchmark loading does not induce load history effects or overload retardation. The typical fracture surface marks are shown in Fig. $3 \mathrm{a}$ and $3 \mathrm{~b}$ for imitation models I and II, respectively.

In this figure, the depth of the quarter-elliptical crack is denoted by $c$, the crack length $a$ is the current crack length monitored using the optical microscope, and the crack length $a_{1}$ is the crack length on the second free surface of the imitation models, which is measured by benchmarks. The crack propagation process in imitation models can be divided into two stages. In the first stage, the quarter-elliptical crack is described by a part-through thickness crack. In the second stage, the quarter-elliptical crack completely crosses the imitation models' thickness and becomes a through-thickness crack.

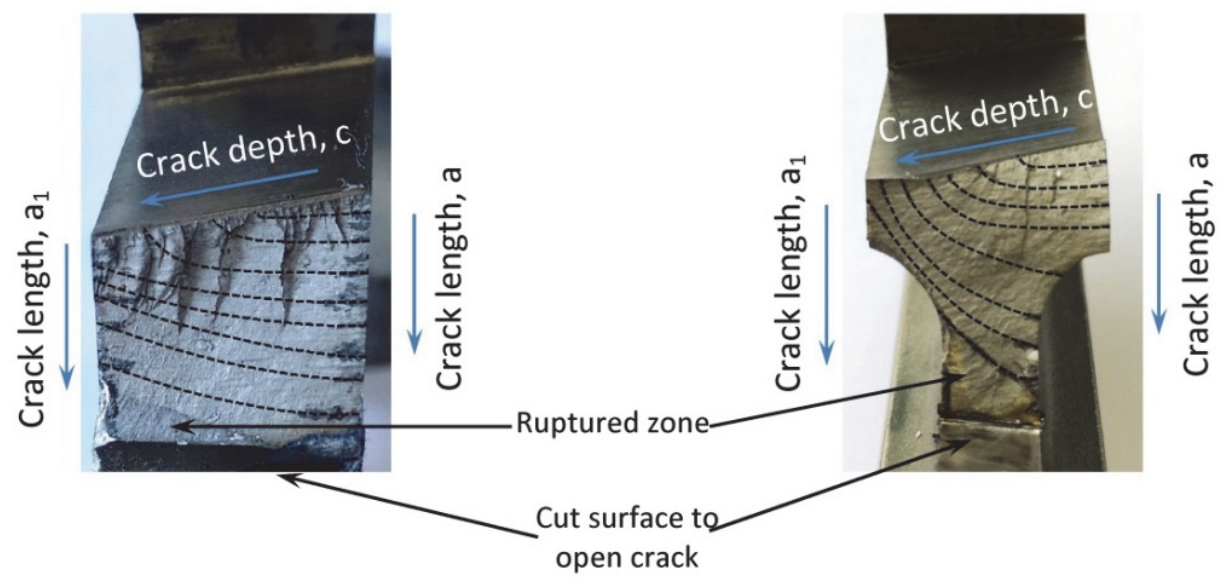

(a)

(b)

Figure 3: Fracture surface for (a) imitation model I and (b) imitation model II. 
The crack front shape and the parameters $a$ and $c$ for the quarter-elliptical part-through thickness cracks, and the parameters $a$ and $a$ for through-thickness cracks were obtained by detailed fracture surface analysis. The combinations of the parameters used in the numerical calculations are presented in Tab. 2.

\begin{tabular}{ccccccc}
\hline \multirow{2}{*}{ Imitation model } & \multicolumn{3}{c}{$\begin{array}{c}\text { Surface crack sizes a/c } \\
(\mathrm{mm} / \mathrm{mm})\end{array}$} & \multicolumn{3}{c}{ Through-thickness crack sizes a/a } \\
& 1st front & 2nd front & 3rd front & 4th front & 5th front & 6th front \\
& $1.79 / 7.5$ & $3.75 / 9.10$ & $5.54 / 13.05$ & $6.75 / 2.20$ & $9.75 / 3.90$ & $12.85 / 7.50$ \\
I & $1.60 / 6.0$ & $5.90 / 11.40$ & $10.40 / 14.50$ & $12.7 / 9.80$ & $13.2 / 10.4$ & $14.45 / 12.1$ \\
\hline II & &
\end{tabular}

Table 2: Experimental crack sizes for imitation models I and II.

Thus, based on obtained experimental data of the crack front locations for various stages of the fatigue failure process, it is possible to calculate the fracture parameter distributions along the crack front in terms of the elastic and plastic SIFs for each imitation model.

\section{NUMERICAL STUDY}

\section{Elastic-plastic stress-strain fields along the crack front}

7 he numerical calculations in this study are concerned with the SSS analysis of imitation models with surface and through-thickness cracks. The ANSYS FE code [32] is used in the mechanical analysis. The loading conditions of biaxial loaded imitation models were evaluated earlier in [11]. The imitation models need to be loaded with forces along the two axes $P_{x}=38 \mathrm{kN}$ and $P_{y}=19 \mathrm{kN}$. In this case, the maximum value of the equivalent stress around the slot key area coincides with the maximum value of the stress in the full-size compressor disc. The SSS of imitation models accurately reproduce the conditions of biaxial loading of the critical zone of the disk and blade attachment. Each of the imitation models reproduces the key slot geometry of the disk and blade dovetail type attachment in the compressor disk and tension load is applied by means of a specially designed loading fixture (Fig. 4).

The crack tip shape, varied from quarter-elliptical to curvilinear through-thickness, has been considered in the present study. The crack sizes for both the imitation models are presented in Tab. 2. Details of the crack initiation zone are presented in Fig. 5b. In this figure, $a$ is the crack length and $c$ is the crack depth. The initial crack inclination (nearly $45^{\circ}$ ) has been defined consistently with the experimental inclination (Fig. 5a).

Twenty nodal solid brick elements with quadratic interpolation were used to mesh the 3D imitation model configurations. The 3D FE model of imitation model I and imitation model II are presented in Fig. 6a and 7a, respectively. In these models, all contact surfaces between the slot surface and the loading fixture use a surface-to-surface formulation since accurate results are expected.

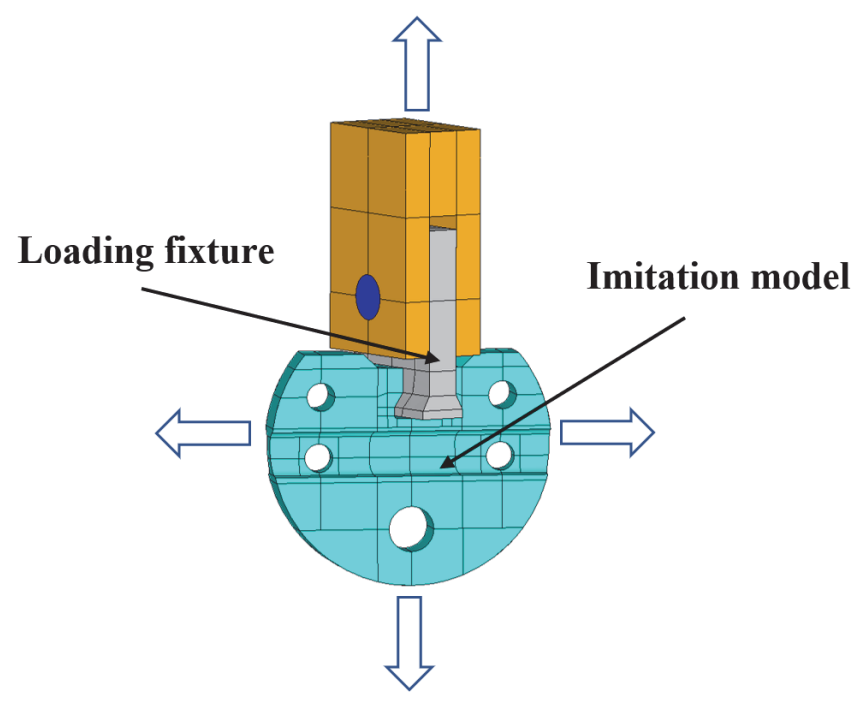

Figure 4: Biaxial loading conditions for imitation models I and II. 


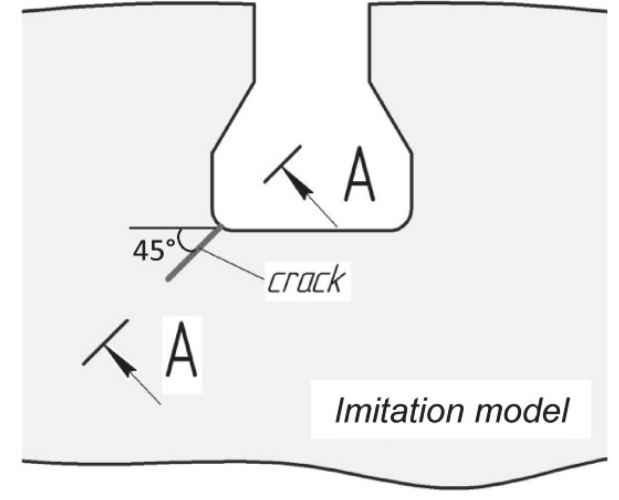

(a)

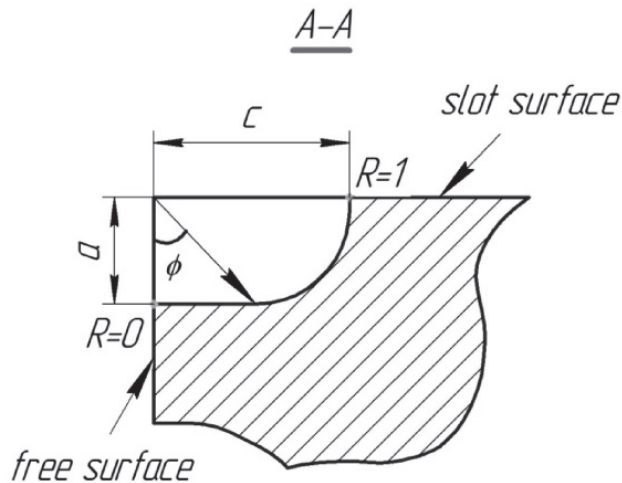

(b)

Figure 5: Details of the crack initiation and growth zone.

Once the location and the size of the crack are identified, the region around the crack needs to be meshed appropriately to accurately calculate the elastic-plastic fracture resistance parameters. In the present study, the SIFs were calculated using the principles of building the topology of FE meshes, the sizes of the elements, and their distribution density in the radial and circumferential directions, as applied to surface defects in real structures and components. These are described in detail in $[13,15,33]$. Thus, with the aim of accurately characterizing the influence of the strain gradient, a very refined mesh is used near the crack tip, where the size of the elements is in the order of a few micrometers. Typical FE meshes for the imitation model I with through-thickness crack and for the imitation model II with surface crack are illustrated in Fig. $6 \mathrm{~b}$ and $7 \mathrm{~b}$, respectively.

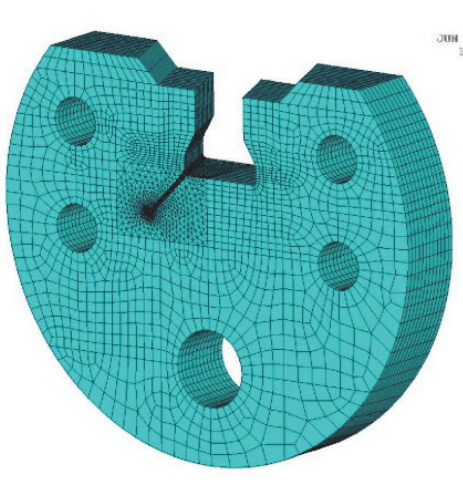

(a)

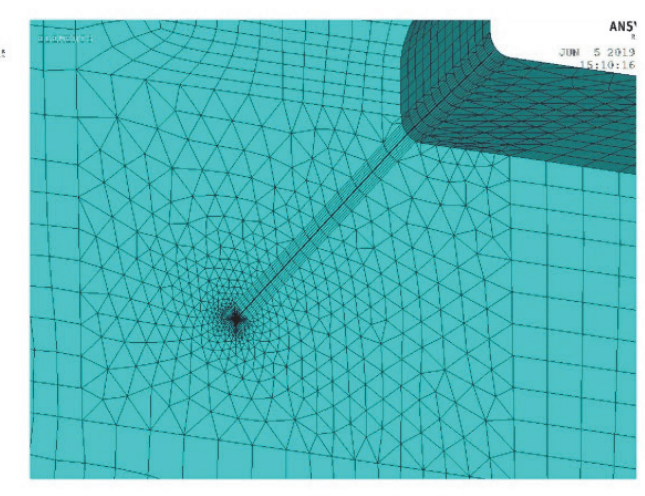

(b)

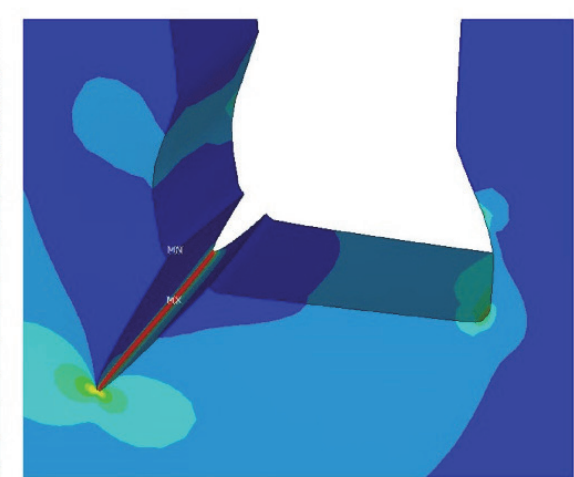

(c)

Figure 6: Typical (a, b) FE meshes and (c) equivalent stress distributions for imitation model I with through-thickness crack.

For each type of imitation model, six 3D FE models with different crack front positions, namely: front 1, front 2, front 3 , front 4 , front 5 , and front 6 , were analyzed for room temperature conditions. The number of nodes in the 3D FE models varied from $2,915,287$ to $3,764,132$, and the minimum size of the $\mathrm{FE}$ was found to be $0.001 \mathrm{~mm}$.

In order to perform numerical calculations, the main mechanical properties listed in Tab. 1 were used. The elastic-plastic material behavior is described by the bilinear kinematic hardening model. The typical equivalent stress distributions for the imitation model I with through-thickness crack (namely front 5), and for the imitation model II with surface crack (namely front 3) are illustrated in Fig. 6c and 7c, respectively.

\section{Stress intensity factors distributions}

One of the main aims of the present study is the calculation of the elastic and plastic fracture mechanical parameters for real shape and sizes of surface and through-thickness cracks, which were obtained by biaxial tests on two types of imitation models. It should be recalled that the imitation model I of constant thickness was used to accurately verify the biaxial loading conditions, and the imitation model II with reduced cross section was proposed in order to fully reproduce 
the cross section of the real compressor disk and the conditions of the mixed mode crack growth. Each imitation model was tested with the same loading conditions.

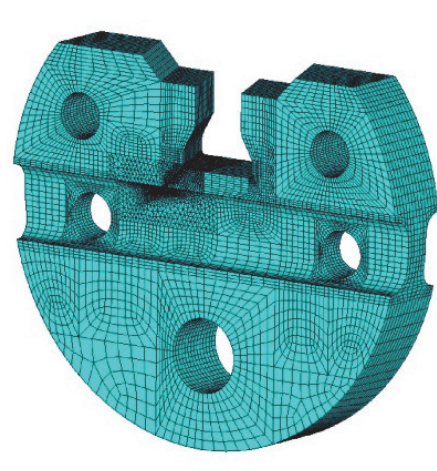

(a)

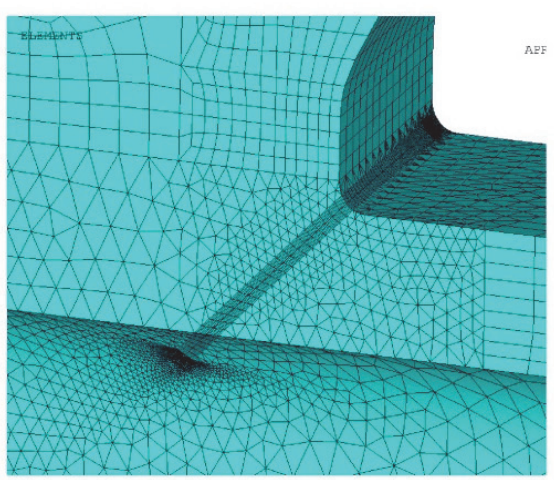

(b)

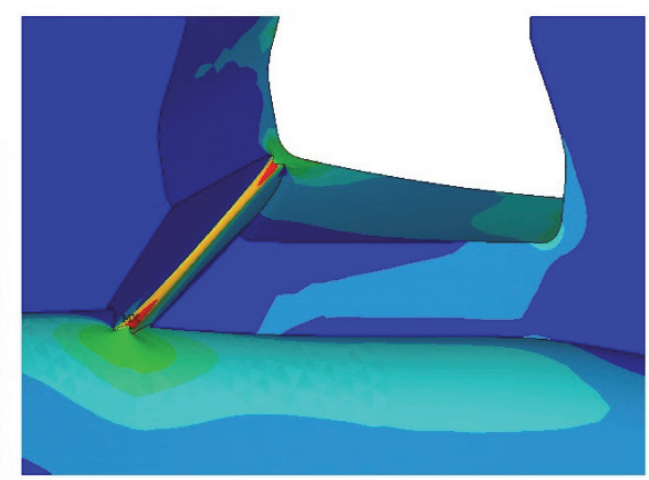

(c)

Figure 7: Typical (a, b) FE meshes and (c) equivalent stress distributions for imitation model II with surface crack.

The description of the elastic and plastic fracture mechanical parameters will be given in terms of the elastic equivalent mixed mode SIF $K_{\text {eqv }}$ and the plastic SIF $K_{M}^{P}$ defined by Eqn. (4) and Eqn. (10), respectively. All parameters are determined at the crack tip distance range $\mathrm{r} / \mathrm{a}=0.0025-0.01$, where the numerical solution provides a stabilized result. To compare the parameter distributions along the corner surface and through-thickness crack tip, it is convenient to introduce dimensionless coordinates in the following form:

$$
\begin{aligned}
x_{0} & =\Delta \varphi \cos \varphi_{0}, y_{0}=\Delta \varphi \sin \varphi_{0}, x_{c}=\Delta \varphi \cos \varphi_{c}, y_{c}=\Delta \varphi \sin \varphi_{c}, x_{i}=\Delta \varphi \cos \varphi_{i}, y_{i}= \\
& =\Delta \varphi \sin \varphi_{i}, \varphi_{i} \in\left[\varphi_{0}, \varphi_{c}\right], \Delta \varphi=\varphi_{c}-\varphi_{0} \\
\bar{X}_{i} & =\frac{x_{0}-x_{i}}{x_{0}-x_{c}}, \bar{Y}_{i}=\frac{y_{i}-y_{0}}{y_{c}-y_{0}}, R_{i}=\frac{1}{\sqrt{2}} \sqrt{\bar{X}_{i}^{2}+Y_{i}^{2}}, R \in[0,1]
\end{aligned}
$$

where $\phi_{0}$ is the angle determining the position of the initial point of the crack tip, and $\phi_{c}$ is the angle corresponding to the last point of the crack tip. In the following representation of the numerical results, the authors will use the variable $\mathrm{R}$ in the 0 to 1 . $R=0$ indicates the exterior free surface of the imitation model, while $R=1$ indicates the slot surface (Fig. $5 b$ ). In the case of through-thickness cracks, $R=1$ indicates the second free surface of the imitation models (Fig. 3a, b).

The distributions of the elastic SIF $K_{\text {eqv }}$ along the surface and through-thickness cracks in the imitation model I are shown in Fig. 8a. Looking at this figure, it can be noted that the elastic SIFs $K_{e q v}$ for the imitation model I are changed by a moderate amount in the range of $38-60 \mathrm{MPa} \cdot \mathrm{m}^{1 / 2}$. The maximum value of the elastic SIFs $K_{\text {eqv }}$ for each considered crack front is in the range of $0<\mathrm{R}<1$, which correspond to the deepest points of crack front. This behavior is observed for conditions of plane strain due to the free-surface effect.

Contrary to this, the distributions of the elastic SIF $K_{\text {eqv }}$ in the imitation model II significantly changes in the range of 50$170 \mathrm{MPa} \cdot \mathrm{m}^{1 / 2}$ (Fig. 8b), and the maximum values are observed at the free surfaces of the crack fronts when $\mathrm{R}=0$ or 1 . This behavior is characteristic of the plane stress conditions due to the reduction of the cross section of imitation model II that coincides with the real compressor disk geometry.

The behaviors of the elastic SIFs $K_{\text {eqv }}$ along the free and slot surfaces of the imitation models under biaxial loading conditions are shown in Fig. 9a and b. In these figures, the crack length $a$ and crack depth $c$ are normalized by the imitation model thickness $t=15 \mathrm{~mm}$. It should be noted that at the same ranges of crack length and crack depth, the elastic SIFs $K_{\text {eqv }}$ are significantly changed for the imitation model II, and they have increasing trends. Looking at these figures and considering changes in the SIFs along the crack front of imitation model II undergoing biaxial loading, differences in the crack growth rate along the external free surface and on the key slot surface are evaluated. It is clear that the imitation model II is more suitable for the experimental determination of durability in the stage of the crack growth, and to predict 
the inclined crack path under mixed mode biaxial loading. For a further description of the crack growth rate under biaxial loading conditions, the mixed mode elastic SIFs $K_{\text {eqv }}$ as a function of the crack size $(a, c)$ can be formulated as polynomial equations.

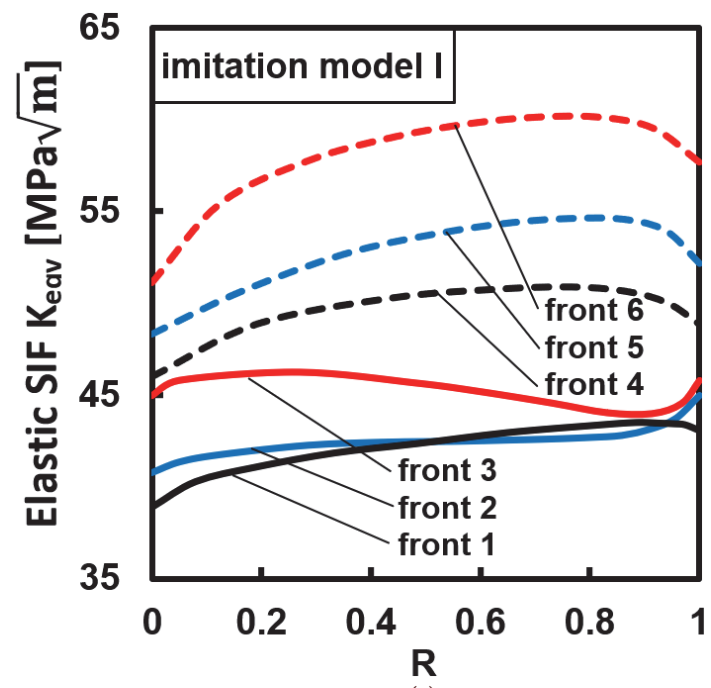

(a)

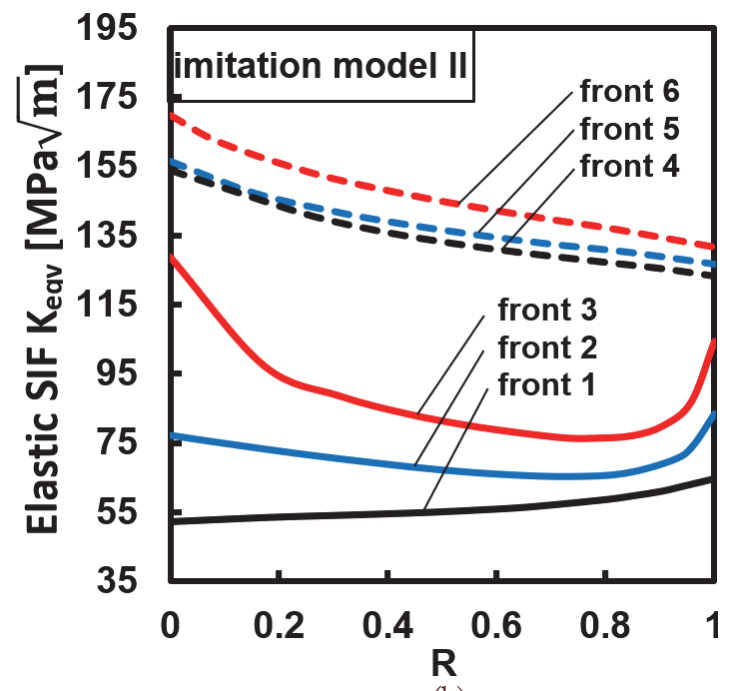

(b)

Figure 8: Distributions of the equivalent elastic SIFs along the crack fronts for (a) imitation model I and (b) imitation model II.

As mentioned above, the nominal stresses in the critical zones of the compressor disk exceed the yield strength of the material [15]. According to the basic principle of imitation modeling [11], the SSSs of critical zones of both the real structural component and the imitation models should be the same. Thus, the imitation model II is also affected by the plastic strains increasing with the largest surface crack sizes. In this case, the distributions of elastic SIFs $K_{\text {equ }}$ should be considered as conditional elastic SIFs, and the application of nonlinear fracture mechanical parameters is important.

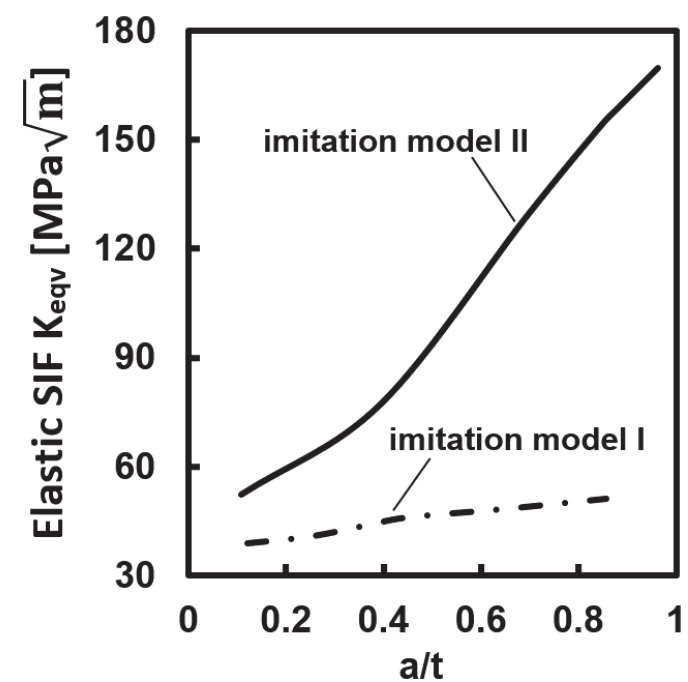

(a)

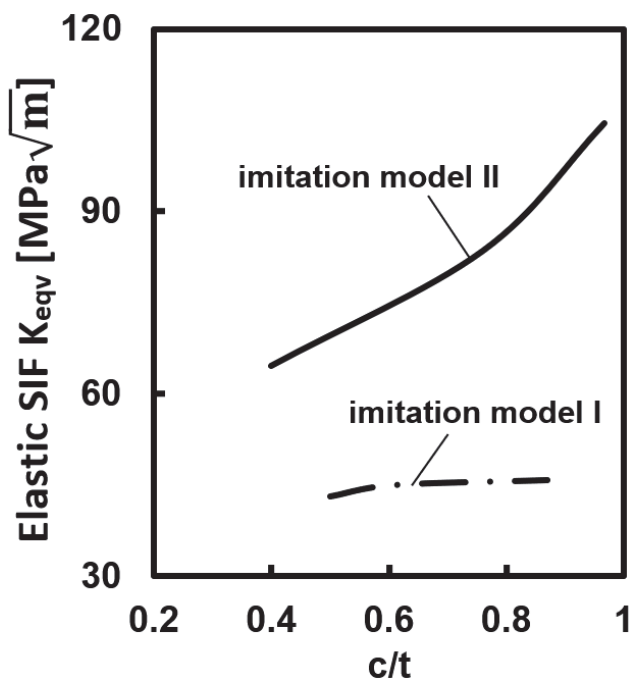

(b)

Figure 9: Comparisons of the equivalent elastic SIFs on (a) the free surface and (b) the slot surface of the crack fronts.

The second parameter related to the fracture resistance of the imitation models is the plastic SIF $K_{M}^{P}$, which was determined using Eqn. (10). In this calculation, in contrast to the elastic state, the effects of the elastic-plastic properties of the titanium alloy VT3-1 according to Tab. 1 by employing the normalizing fatigue $I_{n}\left(\theta^{*}\right.$ )-integral (Eqn. (8)) are considered. Fig. 10a and 10b show the behavior of the dimensionless plastic SIF $K_{M}^{P}$ along the free and slot surfaces of 
imitation models, respectively. In these figures, the crack length $a$ and the crack depth $c$ are normalized by the imitation model thickness $t=15 \mathrm{~mm}$.

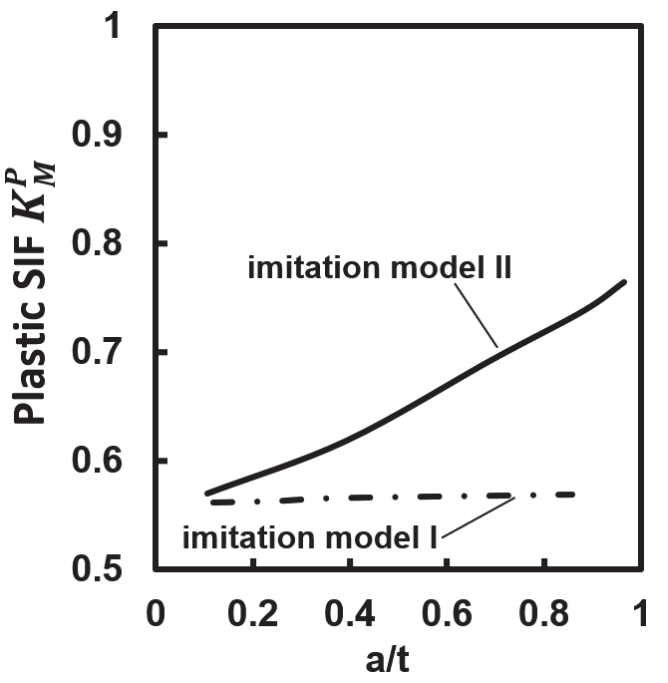

(a)

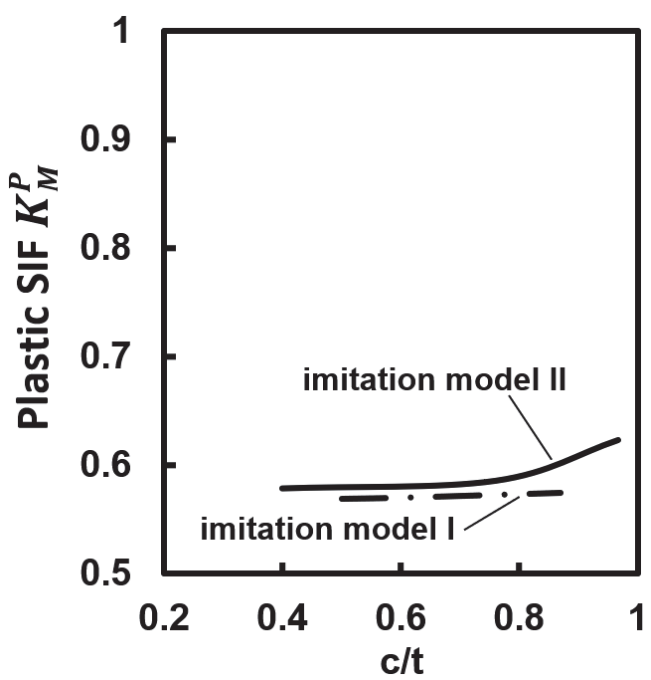

(b)

Figure 10: Comparisons of the plastic SIFs on (a) the free surface and (b) the slot surface of the crack fronts.

In contrast to the elastic SIFs Keqv, the range of the plastic SIF $K_{M}^{P}$ for both imitation models has a very small variation that is limited by the plastic material properties. As expected, a higher SSS of imitation model II leads to higher values of the plastic SIF $K_{M}^{P}$, in comparison with imitation model I.

For a further interpretation of the experimental fatigue fracture diagrams, the mixed mode plastic SIF $K_{M}^{P}$ as a function of the crack size $(a, c)$ in imitation model II can be presented in the form of polynomial equations. Thus, the results of the numerical analyses and experimental research based on the imitation modeling approach can be very useful for verification of modern crack growth rates and lifetime prediction models. Clearly, the plastic SIF $K_{M}^{P}$ is sensitive to the main plastic properties of the material that are described by the yield stress, strain hardening exponent, ultimate tensile strength under monotonic loading, fatigue strength and ductility, cyclic strain hardening exponent, and the strength coefficient. These findings support the use of the plastic SIF as a unified parameter for assessing the fracture resistance of materials and structures.

\section{CONCLUSIONS}

I $\mathrm{n}$ this study, the distributions of elastic and plastic SIFs for two geometries of imitation models of a gas turbine engine compressor disk were determined based on full-size 3D finite element analysis. The biaxial loading conditions were verified on the first imitation model of constant thickness. In order to fully reproduce the geometry of the compressor disk and the conditions of mixed mode crack growth, the second biaxially loaded imitation model with reduced cross section was proposed. Experimental relations between the crack sizes and the aspect ratio were determined by careful analysis of the fracture surfaces of both models. The crack front shape, which varied from surface quarter elliptical to through-thickness cracks, was considered. The advantages of using the computational and experimental results of imitation model II for verification and development of modern crack growth rates and lifetime prediction models were stated.

\section{ACKNOWLEDGMENT} he authors gratefully acknowledge the financial support of the Russian Science Foundation under the Project 19-
$79-10160$. 


\section{REFERENCES}

[1] Carter B.J., Wawrzynek P.A., Ingraffae, A.R. (2000). Automated 3D crack growth simulation, International Journal of Numerical Methods in Engineering, 47, pp. 229-253. DOI: 10.1002/(SICI)1097-0207(20000110/30)47:1/3<229::AID-NME769>3.0.CO;2-2.

[2] Timbrell C, Cook G. (1997). 3-D FE fracture mechanics analysis for industrial applications. Zentech International Limited, UK. Seminar: "Inelastic finite element analysis", Institute of Mechanical Engineering, London, 14 October.

[3] Dassault Systems Simulia Corp. (2011). Abaqus analysis user's manual, Providence, RI, USA.

[4] Schollmann M., Fulland M., Richard H.A. (2003). Development of a new software for adaptive crack growth simulations in 3D structures, Engineering Fracture Mechanics, 70 (2), pp. 249-268. DOI: 10.1016/S0013-7944(02)00028-0.

[5] BEASY (2016). BEASY V10r18 Documentation. C.M. BEASY Ltd.

[6] Richard H.A., Sander M., Schramm B., Kullmer G., Wirxel M. (2013). Fatigue crack growth in real structures, International Journal of Fatigue, 50, pp. 83-88. DOI: 10.1016/j.ijfatigue.2012.02.013.

[7] Gianella V., Perrella M., Shlyannikov V. (2018). Fatigue crack growth in a compressor stage of a turbofan engine by FEM-DBEM approach, Procedia Structural Integrity, 12, pp. 404-415. DOI: 10.1016/j.prostr.2018.11.077.

[8] Gianella V., Citarella R., Perrella M., Shlyannikov V. (2019). Surface crack modelling in an engine compressor disc, Theoretical and Applied Fracture Mechanics, 103, 102279. DOI: 10.1016/j.tafmec.2019.102279.

[9] Stepanov N.V., Shkanov I.N., Omel'chenko V.V., Reznik B.G. (1985). Evaluation of stress state and damage sensitivity equivalence of rotating discs in testing on multiaxial electrohydraulic stand, Soviet Aeronautics, 28(2), pp. 120-123.

[10] Shlyannikov V.N., Iltchenko B.V., Stepanov N.V. (2001). Fracture analysis of turbine disks and computationalexperimental background of the operational decisions, Eng. Failure Analysis, 8, pp. 461-475. DOI: 10.1016/S1350-6307(00)00041-8.

[11] Shlyannikov V.N., Yarullin R.R., Ishtyryakov I.S. (2019). Failure analysis of an aircraft GTE compressor disk on the base of imitation modeling principles, Procedia Structural Integrity, 18, pp. 322-329. DOI: $10.1016 /$ j.prostr.2019.08.172.

[12] Shanyavskiy A.A., Stepanov N.V. (1995). Fractographic analysis of fatigue crack growth in engine compressor disks of Ti-6Al-3Mo-2Cr titanium alloy, Fatigue Fract. Engng. Mater. Struct., 18(5), pp. 539-550. DOI: $10.1111 / j .1460-2695.1995 . t b 01416 . x$.

[13] V.N. Shlyannikov, A.P. Zakharov, R.R. Yarullin. (2016). Structural integrity assessment of turbine disk on a plastic stress intensity factor basis, Int J Fatigue, 92(1), pp. 234-245. DOI: 10.1016/j.ijfatigue.2016.07.016.

[14] Shlyannikov V.N., Zakharov A.P. (2017). Generalization of mixed mode crack behaviour by the plastic stress intensity factor, Theoret. Appl. Fract. Mech., 91, pp. 52-65. DOI: 10.1016/j.tafmec.2017.03.014.

[15] Shlyannikov VN, Ishtyryakov IS. (2019). Crack growth rate and lifetime prediction for aviation gas turbine engine compressor disk based on nonlinear fracture mechanics parameters, Theoret. Appl. Fract. Mech., 103, 102313. DOI: 10.1016/j.tafmec.2019.102313.

[16] Zerres P., Vormland M. (2012). Finite element based simulation of fatigue crack growth with a focus on elastic-plastic material behavior, Computational Materials Science, 57, pp. 73-79. DOI: 10.1016/j.commatsci.2012.01.018.

[17] Bonnand V., Chaboche J.1., Gomez P., Kanoute P., Pacou D. (2011). Investigation of multiaxial fatigue in the context of turboengine disc applications, International Journal of Fatigue, 33, pp. 1006-1016. DOI: 10.1016/j.ijfatigue.2010.12.018.

[18] Yarullin R.R., Zakharov A.P., Ishtyryakov I.S. (2018). Nonlinear fracture resistance parameters for cracked aircraft GTE compressor disk, Procedia Structural Integity, 13, pp. 902-907. DOI: 10.1016/j.prostr.2018.12.170.

[19] Henry BS, Luxmoore AR. (1997). The stress triaxiality constraint and the Q-value as ductile fracture parameter, Eng. Fract. Mech., 57, pp. 375-390. DOI: 10.1016/S0013-7944(97)00031-3.

[20] Richard H.A., Eberlein A., Kullmer G. (2017). Concepts and experimental results for stable and unstable crack growth under 3D-mixed-mode-loadings, Engineering Fracture Mechanics, 174, pp. 10-20.

DOI: 10.1016/j.engfracmech.2016.12.005.

[21] Shlyannikov V.N. (2013). T-stress for crack paths in test specimens subject to mixed mode loading, Eng. Fract. Mech., 108, pp. 3-18. DOI: 10.1016/j.engfracmech.2013.03.011.

[22] Chang J, Xu J, Mutoh Y. (2006). A general mixed-mode brittle fracture criterion for cracked materials, Engng. Fract. Mech., 73, pp. 1249-63. DOI: 10.1016/j.engfracmech.2005.12.011. 
[23] V.N. Shlyannikov, R.R. Yarullin, I. Ishtyryakov. (2018). Effect of temperature on the growth of fatigue surface cracks in aluminum alloys, Theoret. Appl. Fract. Mech., 96, pp. 758-767. DOI: 10.1016/j.tafmec.2017.11.003.

[24] Rigby RH, Aliabadi MH. (1998). Decomposition of the mixed-mode J-integral - Revisited, Int. Journ. Solid Struct., 17, pp. 2073-2099. DOI: 10.1016/S0020-7683(97)00171-6.

[25] Hutchinson JW. (1968). Singular behaviour at the end of a tensile crack in a hardening material, J. Mech. Phys. Solids, 16, pp. 13-31. DOI: 10.1016/0022-5096(68)90014-8.

[26] Hutchinson JW. (1968). Plastic stress and strain fields at a crack tip, J. Mech. Phys. Solids, 16, pp. 337-347. DOI: 10.1016/0022-5096(68)90021-5.

[27] Shih CF. (1974). Small-scale yielding analysis of mixed mode plane-strain crack problems, ASTM STP 560, pp. 187210. DOI: $10.1520 /$ STP33141S.

[28] Shlyannikov VN, Tumanov AV. (2011). An inclined surface crack subject to biaxial loading, Int. J. Solids Struct., 48, pp. 1778-1790. DOI: 10.1016/j.ijsolstr.2011.02.024.

[29] V.N. Shlyannikov, A.V. Tumanov. (2014). Characterization of crack tip stress fields in test specimens using mode mixity parameters, Int J Fract., 185, pp. 49-76. DOI: 10.1007/s10704-013-9898-0.

[30] Slyannikov VN, Yarullin RR, Ishtyryakov IS. (2015). Surface crack growth in cylindrical hollow specimen subject to tension and torsion, Frattura ed Integrita Structurale, 33, pp. 335-344. DOI: 10.3221/IGF-ESIS.33.37.

[31] Yarullin RR, Ishtyryakov IS. (2016). Fatigue Surface Crack Growth in Aluminum Alloys under Different Temperatures, Procedia Engineering, 160, pp. 199-206. DOI: 10.1016/j.proeng.2016.08.881.

[32] ANSYS. (2009). Theory Reference for the Mechanical APDL and Mechanical Applications. Release 12.0. Available at: http://dl.mycivil.ir/reza/ans_thry.pdf.

[33] Shlyannikov VN, Ishtyryakov IS, Tumanov AV. (2020). Characterization of the nonlinear fracture resistance parameters for an aviation GTE turbine disc, Fatigue Fract. Eng. Mater. Struct., 43, pp. 1-17.

DOI: $10.1111 /$ ffe. 13188 . 